\title{
Peri-Annular and Septal Abscesses in Infectious Endocarditis. About 3 Cases Observed at the University Hospital of Brazzaville
}

\author{
Solange Flore Mongo Ngamami ${ }^{1,2}$, Armel Landry Batchi-Bouyou ${ }^{1 *}$, Trésor Mavie Eouolo Ndona ${ }^{1}$, \\ Christian Michel Kouala Landa, ${ }^{1,2}$, Eric Gibrel Kimbally Kaky,2, Jean Joseph Ekwa Sima1, \\ Bertrand Fikahem Ellenga Mbolla', ${ }^{1,2}$ Méo Stéphane Ikama ${ }^{1,2}$
}

${ }^{1}$ Department of Cardiology, University Hospital of Brazzaville, Brazzaville, Republic of the Congo ${ }^{2}$ Department of Doctoral Studies, Faculty of Health Sciences, Marien Ngouabi University, Brazzaville, Republic of the Congo Email: *armel_b@hotmail.fr

How to cite this paper: Ngamami, S.F.M., Batchi-Bouyou, A.L., Ndona, T.M.E., Landa, C.M.K., Kaky, E.G.K., Sima, J.J.E., Mbolla, B.F.E. and Ikama, M.S. (2022) Peri-Annular and Septal Abscesses in Infectious Endocarditis. About 3 Cases Observed at the University Hospital of Brazzaville. World Journal of Cardiovascular Diseases, 12, 94-110. https://doi.org/10.4236/wjcd.2022.122010

Received: December 31, 2021

Accepted: February 19, 2022

Published: February 22, 2022

Copyright $\odot 2022$ by author(s) and Scientific Research Publishing Inc. This work is licensed under the Creative Commons Attribution International License (CC BY 4.0).

http://creativecommons.org/licenses/by/4.0/

(c) (i) Open Access

\begin{abstract}
Infectious endocarditis (IE) is a relatively rare but serious condition. We report 3 cases of infectious endocarditis complicated by peri-annular and/or septal abscess. The patients aged 24, 25 and 28 were all male. Global heart failure was observed in 2 cases. Atrioventricular block was noted in 2 cases (complete syncopation: 1 time; 2nd degree Mobitz 21 time). Transthoracic echocardiography made it possible to diagnose abscess in all cases (aortic and septal peri-annulus: once, septal only: twice). The aortic insufficiency was grade 2 in all cases, mitral insufficiency grade 2 in 1 . The front door was found once, with a dental location. Blood cultures were negative in all cases. A bi-probabilistic antibiotic therapy made it possible to control the infectious process in all the patients. Cardiac surgery, indicated in all cases, was performed in 1 case, consisting of flattening the abscesses and then placing a pacemaker in the patient with complete syncopal atrioventricular block. The outcome of all patients was favorable. Return to permanent sinus rhythm, associated with complete left bundle branch block, was noted at the 4th year of development in the pacemaker wearer. The other 2 patients are still awaiting medical evacuation.
\end{abstract}

\section{Keywords}

Infectious Endocarditis, Peri-Annular and Septal Abscess, Echocardiography, Treatment

\section{Introduction}

Infectious endocarditis (IE) is a relatively rare but serious condition [1]. Also 
called Osler's disease, it is the consequence of the invasion, and the spread of a microorganism in the heart valves, most often following bacteremia. It is clinically characterized by a combination of fever and a heart murmur [1] [2].

Transesophageal echocardiography (TEE) is the diagnostic tool of choice for infective endocarditis with high sensitivity in the range of $80 \%$ to $100 \%$ [3].

Aortic localization is the most frequent with more than $50 \%$ of cases [4]. Heart failure is seen in $50 \%-60 \%$ of cases, and is more often seen when IE involves the aortic valve (29\%) than the mitral valve (20\%). Aortic localization is characterized by its progression to myocardial failure and the high number of complications [5].

The spread of infection during AI can be towards the central fibrous nucleus and the upper part of the interventricular septum which can lead to damage to the atrioventricular and intraventricular conduction pathways [6] [7].

In addition, heart abscesses in $20 \%$ to $30 \%$ of cases result from the spread of infection to anatomical structures located in contact with the valves. These abscesses, in particular those which destroy the fibrous valvular rings, constitute an operative difficulty. The germs can be trapped in the fibrous or fibro-calcareous healing tissue. This explains certain relapses and recurrences of infectious endocarditis [7].

In the Republic of Congo, the management of IE with septal involvement remains medical. One case was observed in the series of 39 cases reported by Bouramoue et al. [8]. With heart surgery not yet operational, high-income patients are going abroad.

We report 3 cases of infectious endocarditis complicated by peri-annular and/or septal abscess.

\section{Case Reports}

\subsection{Case Report I}

A 24-year-old man, graduate in Banking and Insurance, jobless, single, without children was admitted in the Department of Cardiology and Internal Medicine of the University Hospital of Brazzaville for a sudden onset syncope, associated with an unstated fever, evolving for about a month. The sudden onset fever with chills and sweating had been treated on an outpatient basis with anti-malaria, then antibiotics. The patient reported one week before admission, palpitations, two episodes of puncture syncope and arthromyalgia.

On admission temperature was $39^{\circ} \mathrm{C}$ and the respiratory rate was 16 cycles/min. The heart rate was 40 beats/min, the BP 120/70 mm Hg. Cardiac auscultation showed a diastolic murmur of 2/6th aortic failure. The pleuropulmonary examination was normal. Hackett's type 2 splenomegaly was noted.

The frontal chest X-ray showed a heart of normal volume (CTR $=50 \%)$, the lungs, pleura and pulmonary vascularization were also normal. The electrocardiogram (ECG) showed bradycardia at 34 beats/min, complete atrioventricular block (AVB), (Figure 1). 


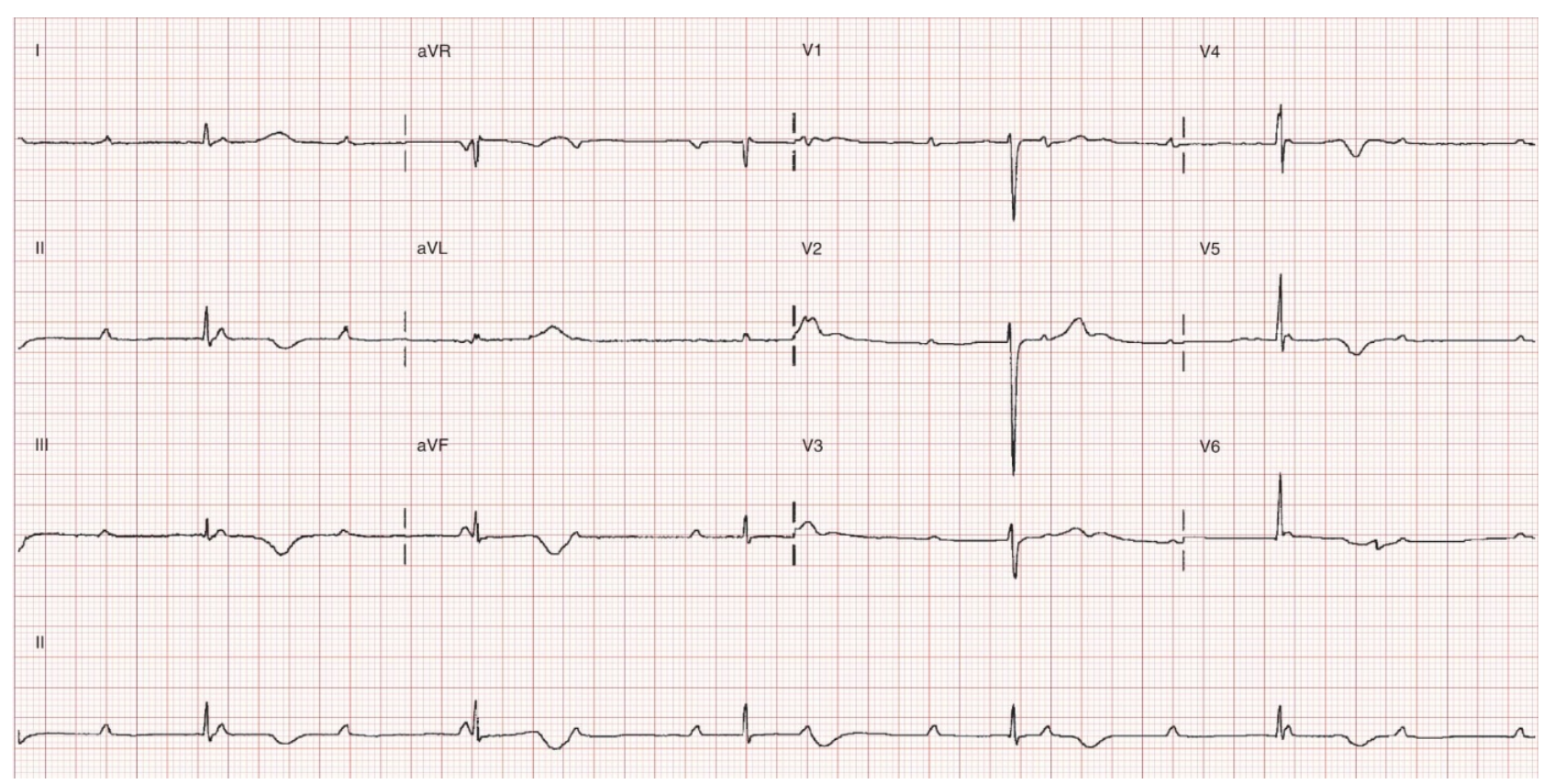

Figure 1. Electrocardiogram showing complete atrioventricular block.

Two-dimensional transthoracic echocardiography coupled with Doppler revealed: thickened aortic sigmoid, absence of vegetations, a left ventricle of normal size, a left ventricular ejection fraction (LVEF) at $71 \%$, an aortic peri-annular abscess and two septate abscesses of the interventricular septum (Figure 2 and Figure 3).

The aortic insufficiency was grade 2 on pulsed Döppler. The mitral profile was of the relaxation disorder type. Pulmonary artery pressure (PAP) was normal.

The biological assessment revealed: two negative blood cultures, a negative retroviral serology (HIV), a C-reactive protein (CRP) at $24 \mathrm{mg} / \mathrm{l}$ and a sedimentation rate at $90 \mathrm{~mm}$, a leukocytosis at 12,000 elements $/ \mathrm{mm}^{3}$. Hemoglobin was $12.1 \mathrm{~g} / \mathrm{dl}$, platelets $200,000 \mathrm{cells} / \mathrm{mm}^{3}$, and fasting blood sugar was $0.81 \mathrm{~g} / \mathrm{l}$. The urine cytobacteriologic examination (ECBU) was sterile.

The diagnosis of infectious aortic endocarditis on a native valve complicated by peri-annular and septal abscess was suggested and retained according to Duke's criteria. A complete syncopal AVB was associated.

The medical treatment combined: a sodium-reduced diet, dual antibiotic therapy (ceftriaxone $3 \mathrm{~g} /$ day for six weeks, and gentamycin $160 \mathrm{mg} /$ day for two weeks), a converting enzyme inhibitor (Enalapril $10 \mathrm{mg} /$ day). Bacteriological control of the infection at the end of treatment was not possible. Cardiac surgery was urgently chosen for the removal of the abscesses and the installation of a permanent pacemaker.

Due to insufficient technical facilities, and taking advantage of family reunification, subsequent care was provided in South Africa. It consisted of surgery under cardiopulmonary bypass to flatten the abscesses a month and a half after discharge. Six weeks later, a Biotronik brand single chamber pacemaker was fitted. 


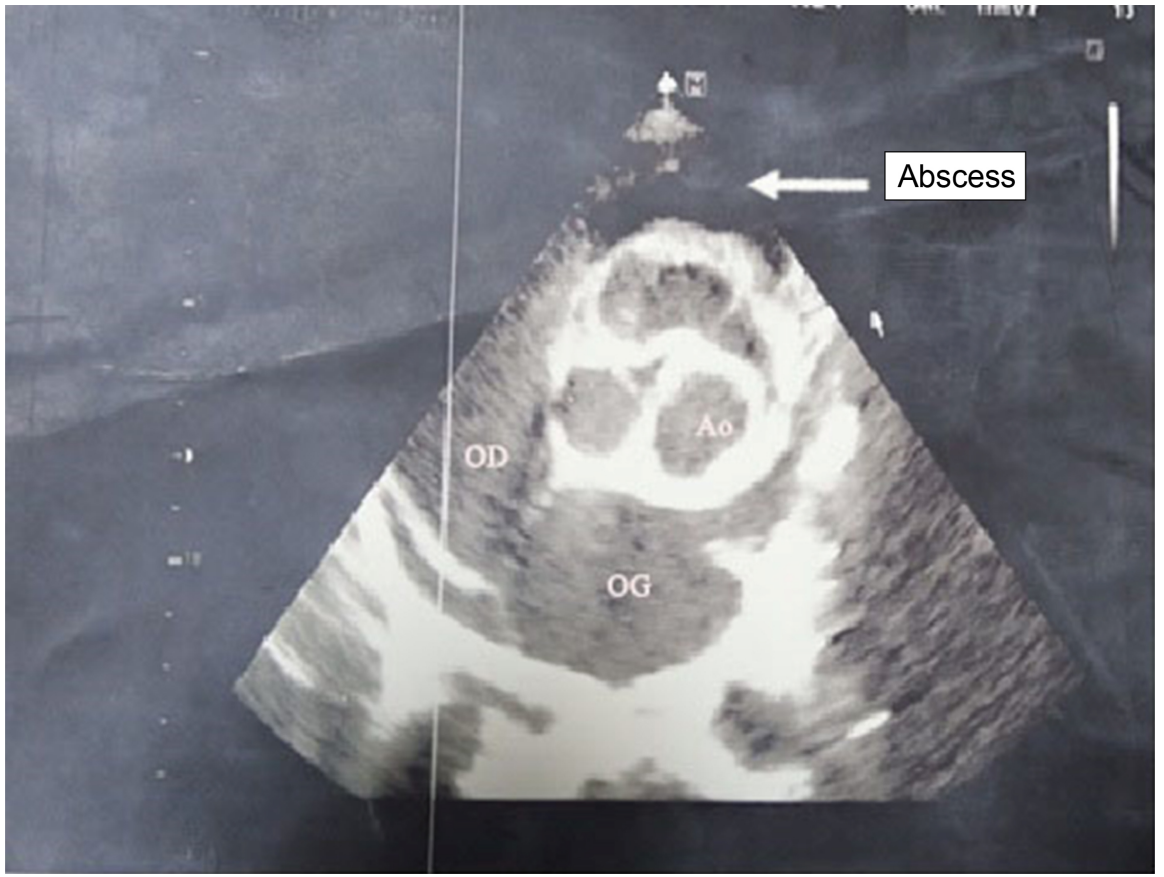

Figure 2. 2D transthoracic echocardiogram (TTE), trans aortic section showing peri-annular aortic abscess.

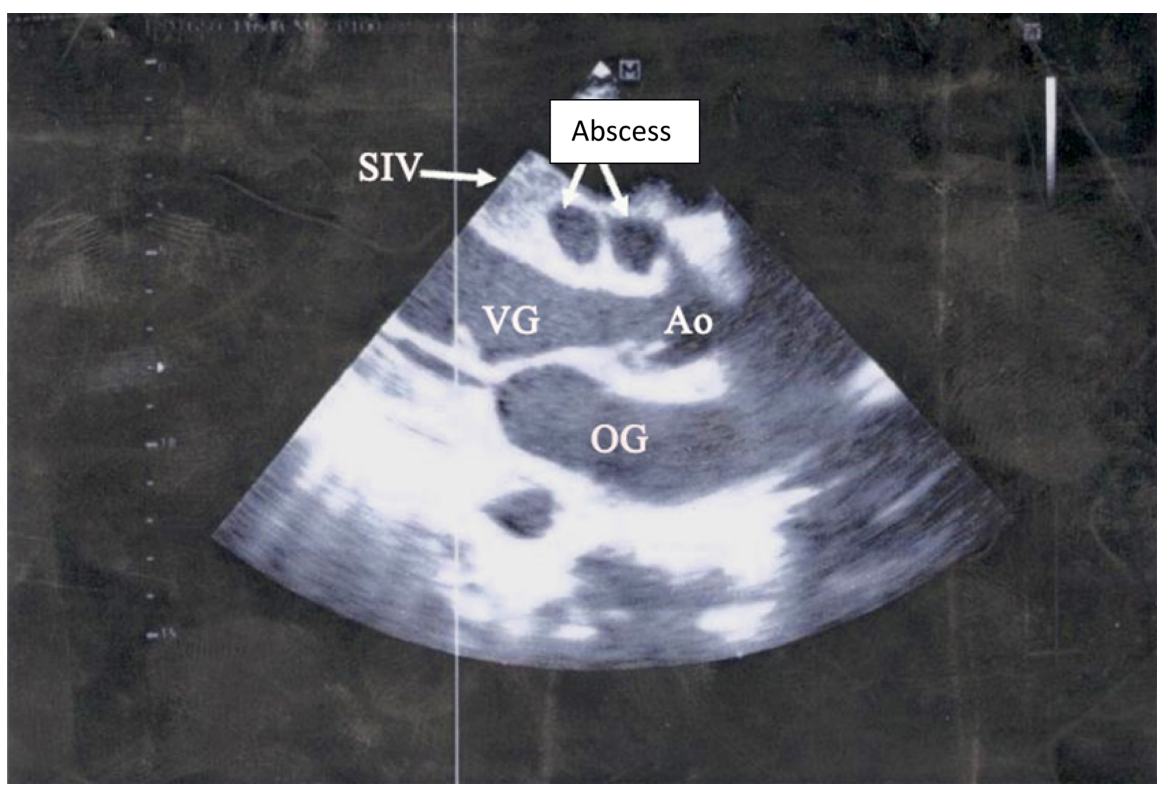

Figure 3. 2D TTE, long axis section showing septic septum abscess.

The frontal chest x-ray taken postoperatively (Figure 4) showed the pacemaker and the endocavitary stimulation probe.

The follow-up ECG one year after pacemaker insertion showed regular electro systolic training (Figure 5).

At the check-up on August 5, 2021, the patient was asymptomatic and in good hemodynamic condition. The heart rate was regular and the cardiac auscultation was normal. 


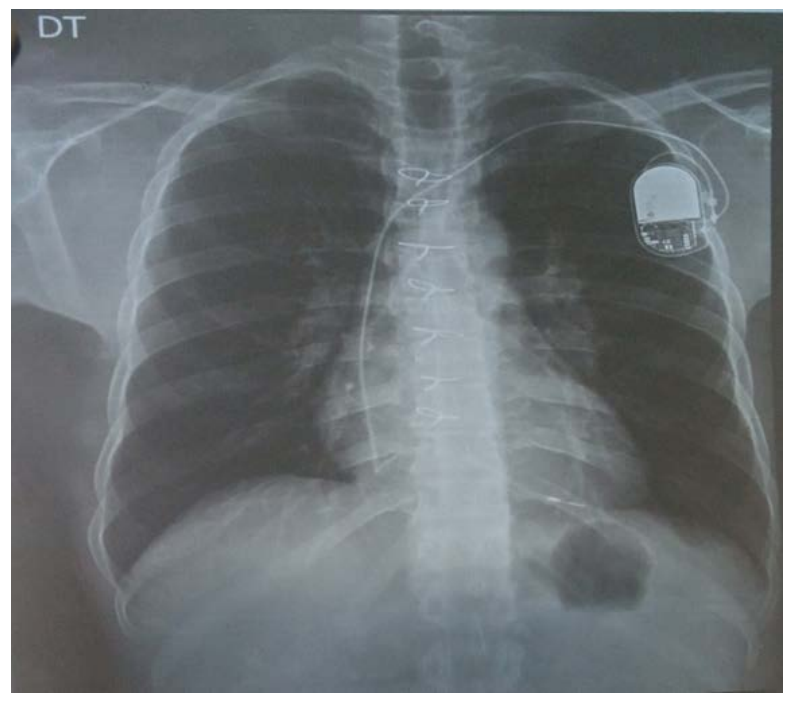

Figure 4. Frontal chest radiograph showing an inserted pacemaker.

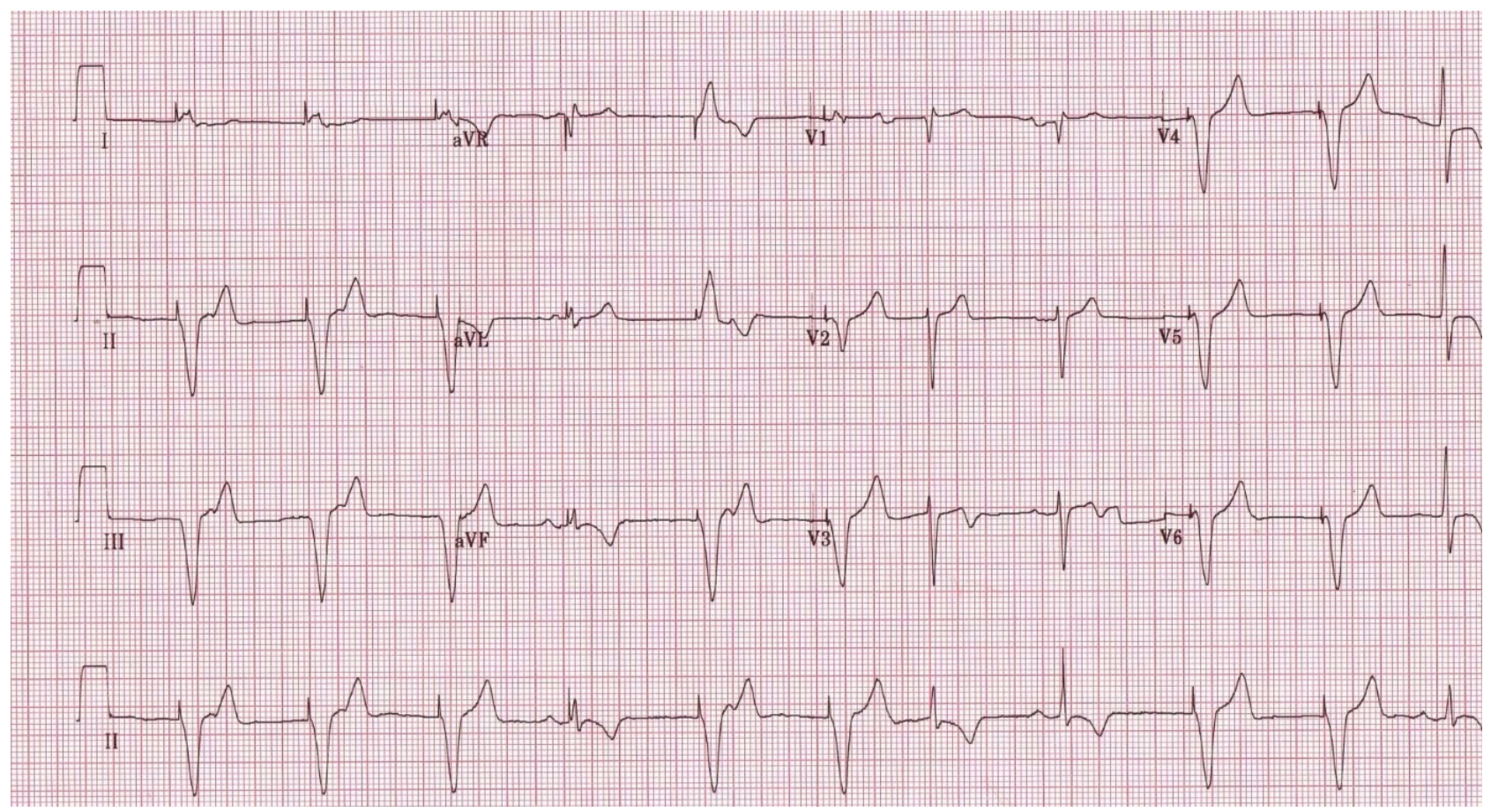

Figure 5. ECG showing stimulation spikes.

The 08/05/2021 check-up ECG (Figure 6) showed sinus rhythm, complete Left bundle block and no spike.

The echocardiogram of 05/08/2021 (Figure 7) showed undilated cardiac chambers and the pulsed Doppler objectified grade 1 or 2 aortic insufficiency. The medical treatment based on enalapril, is continued to this day.

\subsection{Case Report II}

A 28-year-old patient, single, without children, uneducated and unemployed, 


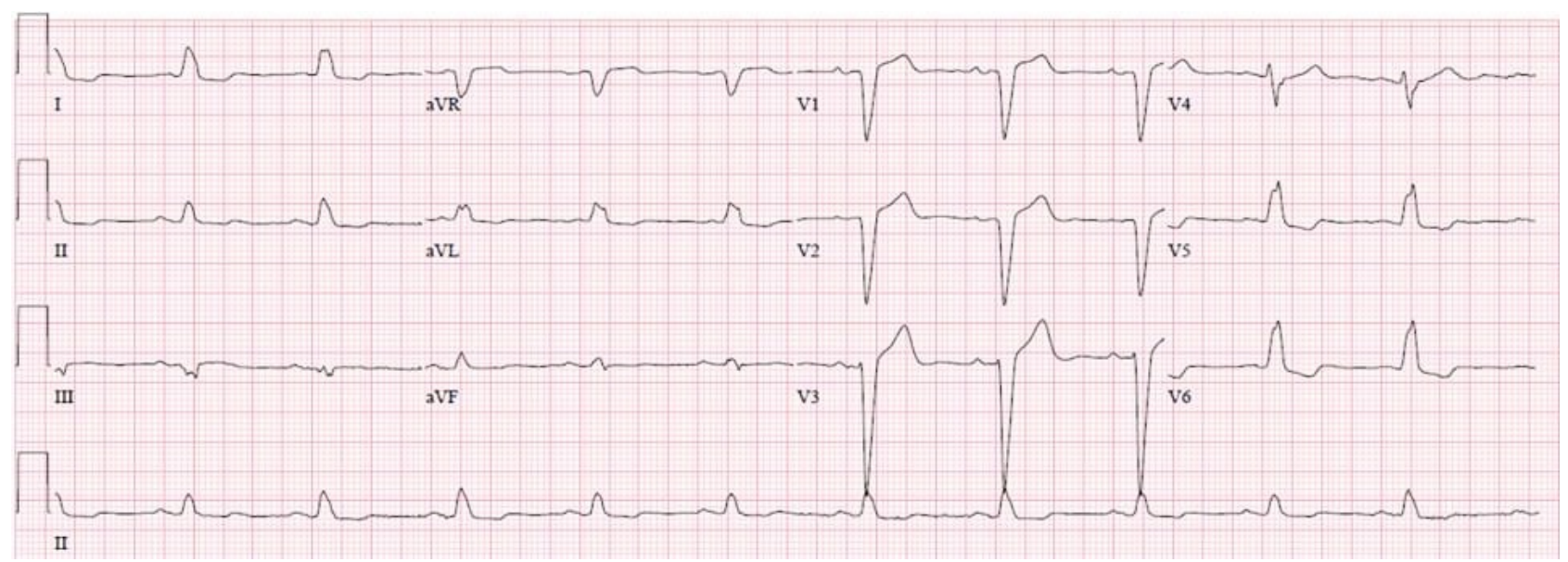

Figure 6. Electrocardiogram at 4 years after the installation of the pace maker showing sinus rhythm, left bundle branch block.

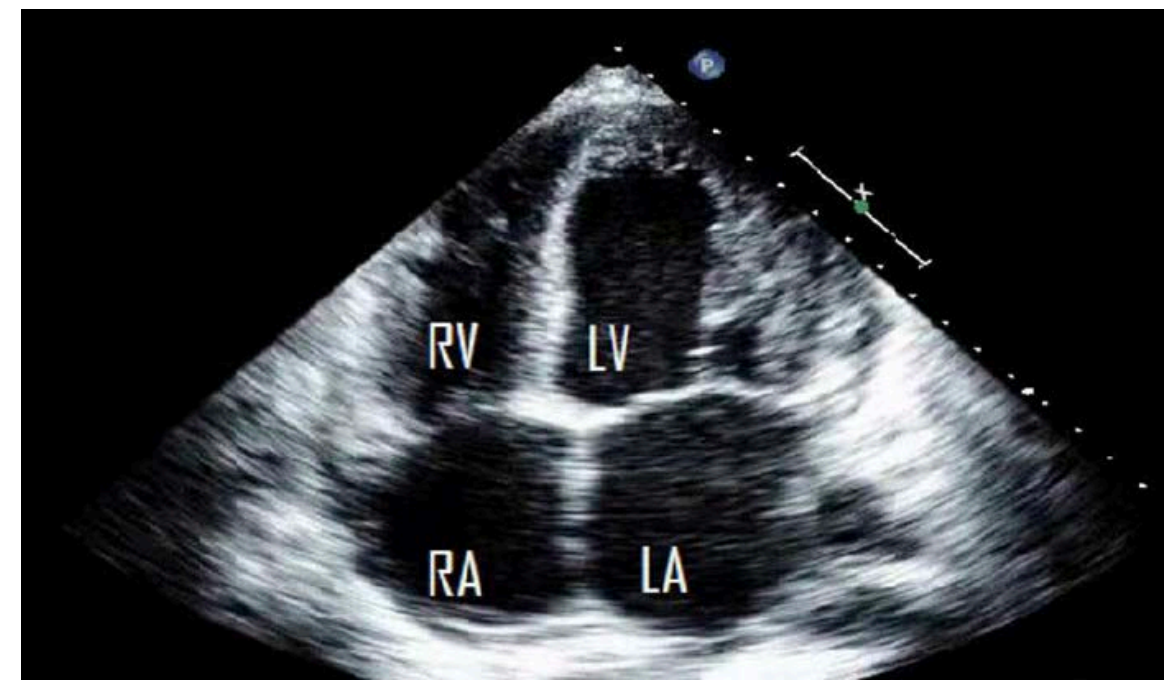

Figure 7. Echocardiography. Apical section showing unexpanded heart chambers.

residing in Brazzaville, referred to the department of Cardiology and Internal Medicine of the University Hospital of Brazzaville for an infectious endocarditis.

No history of chronic inflammatory disease, recurrent angina and polyarthralgia in childhood has been noted. The patient was neither hypertensive nor diabetic. He neither consumed alcoholic beverages nor smoked.

Symptoms dated to about five weeks before admission with the gradual onset of NYHA stage II exertional dyspnea that progressed to NYHA stage IV resting dyspnea. It was associated with an oscillating fever with peaks at $40^{\circ} \mathrm{C}$, chills and a fatty cough bringing back foamy sputum.

These symptoms prompted a visit to a local clinic, where the diagnosis of infectious endocarditis complicated by aortic abscess and heart failure was made. A treatment included a dual antibiotic therapy based on ceftriaxone $3 \mathrm{~g} /$ day and gentamycin $160 \mathrm{mg} /$ day combined with captopril $25 \mathrm{mg} \times 2 /$ day and furosemide $40 \mathrm{mg}$ /day parenterally was administered.

The persistence of the clinical presentation required a consultation twelve 
days later at the Emergency Department of the University Hospital of Brazzaville, then his admission to the department of cardiology.

The vital signs at the entry were: a respiratory rate at $40 \mathrm{cycles} / \mathrm{min}$, an oxygen saturation at $98 \%$ in ambient air, a weight of $42 \mathrm{~kg}$ (previous weight $70 \mathrm{~kg}$, that is to say a loss of $28 \mathrm{~kg}$ ), a height of $1.68 \mathrm{~cm}, \mathrm{BMI}=14.88 \mathrm{Kg} / \mathrm{m}^{2}$, a temperature at $40^{\circ} \mathrm{C}$ and a BP at $120 / 60 \mathrm{~mm} \mathrm{Hg}$.

The rest of the examination showed a chest of normal configuration, well-perceived heart sounds, a regular heart rate at 40 beats $/ \mathrm{min}$, a diastolic murmur of 3/6 aortic insufficiency and the absence of pericardial friction. The patient presented with bilateral crackling rales, hepatomegaly with a hepatic arrow at $16 \mathrm{~cm}$, lower-extremity edema, painless and keeping the cup. The skin and appendage examination was normal.

The oropharyngeal examination revealed: tartar, multiple decayed teeth 47-21-11-26 (chicot), 14 - 17 (dilapidated) and cervical caries of the 42. The infectious port of entry was dental. The ENT examination and the other organs were normal.

The chest $\mathrm{x}$-ray (Figure 8 ) showed significant cardiomegaly $(\mathrm{CTR}=70 \%)$, venous redistribution towards the peaks, capillary venous hypertension, absence of pleural effusion.

The ECG, Figure 9 showed bradycardia at 42 beats/min related to a 2 nd degree AVB, type 2 from MOBITZ.

Two-dimensional trans-thoracic cardiac ultrasound coupled with Doppler revealed a $68 \%$ left ventricular ejection fraction (LVEF), dilated left cardiac chambers, the presence of three empty echo images at the expense of the basal septum extending to the base of the aortic cusps interfering with their opening. Partitioned abscesses were mentioned. The aortic insufficiency was grade 2 on doppler. PAP was normal. The wall thicknesses were normal, the pericardium free and the inferior vena cava dilated.

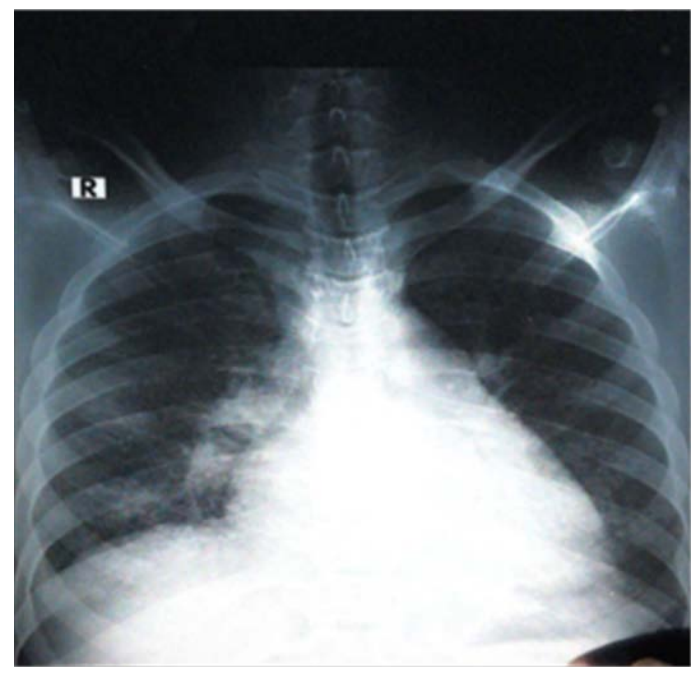

Figure 8. Frontal chest $\mathrm{x}$-ray showing cardiomegaly and hilar stasis. 


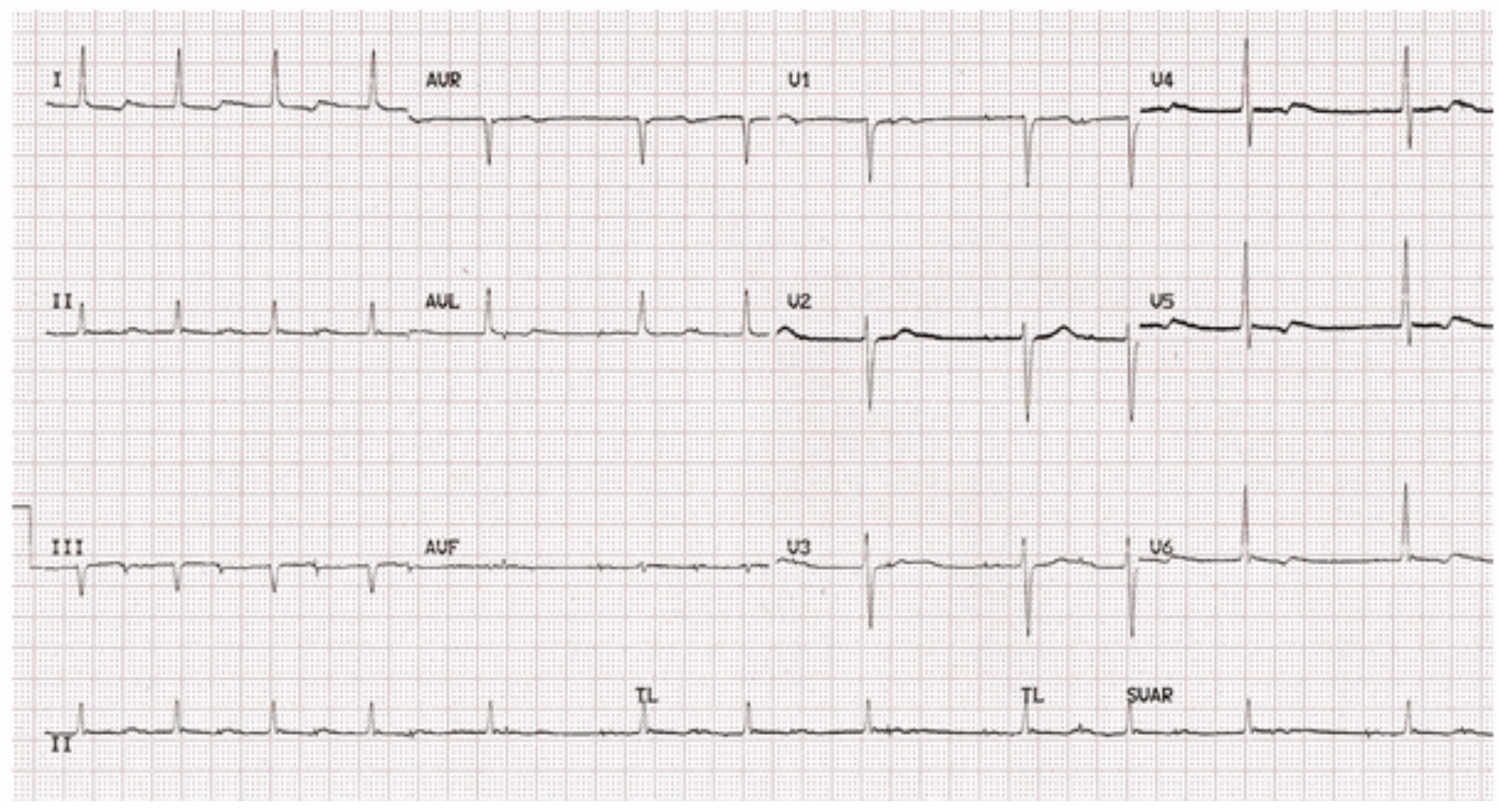

Figure 9. Electrocardiogram showing a 2nd degree AVB.

The interventricular (SIV) septum abscess is shown in Figure 10.

- Laboratory examinations noted: two negative blood cultures, negative retroviral (HIV) serology, CRP at $63.14 \mathrm{mg} / \mathrm{l}, \mathrm{ESR}$ at $45 \mathrm{~mm}$, leucocytes at 11,000 elements $/ \mathrm{mm}^{3}$. The hemoglobin level was $11.7 \mathrm{~g} / \mathrm{dl}$, the platelets at 20.0000 elements $/ \mathrm{mm}^{3}$ and the fasting blood sugar level at $0.81 \mathrm{~g} / \mathrm{l}$.

- The diagnosis retained was an infectious aortic endocarditis on native valve with a global heart failure, septal abscesses, a 2nd degree AVB type 2 of MOBITZ.

- The medical treatment included: the sodium-reduced diet, a bi-antibiotic therapy ceftriaxone $3 \mathrm{~g} /$ day for six weeks and gentamycin $160 \mathrm{mg} /$ day for two weeks, captopril $50 \mathrm{mg} /$ day, furosemide $40 \mathrm{mg} /$ day parenterally. The additional treatment was stomatological, consisting of: twice daily mouthwashes, scaling, dental extractions associated with the administration of antibiotics based on: amoxicillin and clavulanic acid $3 \mathrm{~g} /$ day, metronidazole $1.5 \mathrm{~g} /$ day.

- The course was marked by thermal defervescence and regression of signs of heart failure.

Due to the inadequacy of the technical platform, a medical evacuation was chosen, for the performance of emergency cardiac surgery in order to flatten the abscesses, and to proceed with an aortic valve replacement and a pacemaker installation. in case of worsening of the AVB.

Maintenance therapy included: captopril $100 \mathrm{mg}$ /day; furosemide $20 \mathrm{mg}$ /day; bricanyl LP $10 \mathrm{mg} /$ day. A monthly check-up at CHU-B was recommended, pending patient management. The outcome at one year was favorable (good hemodynamic condition, return to sinus rhythm). 


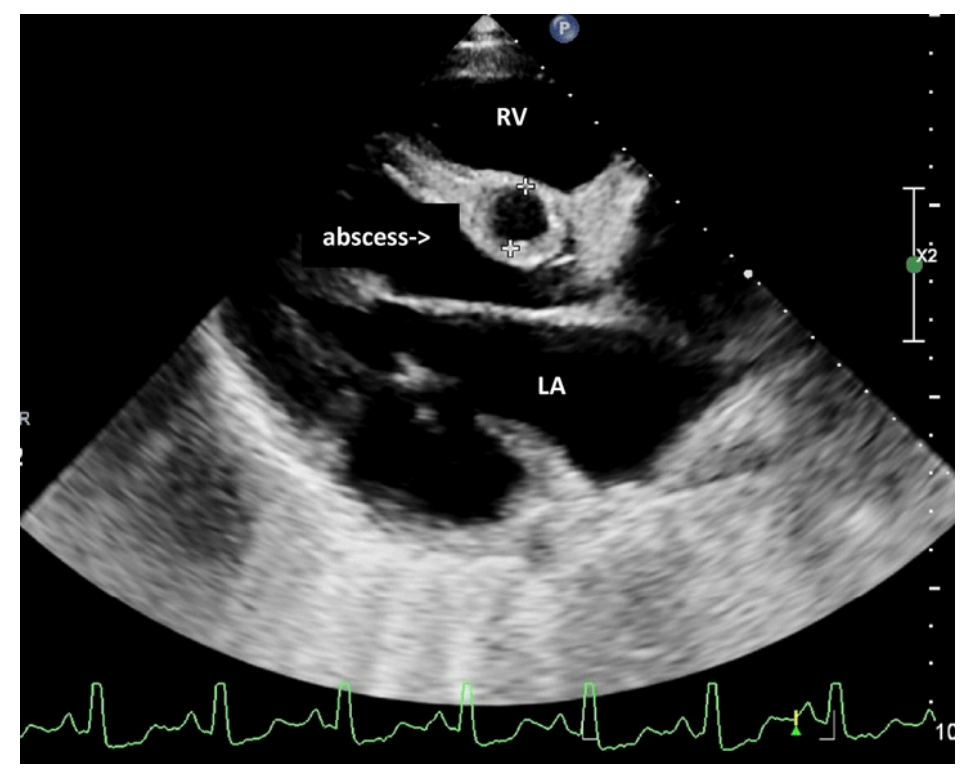

Figure 10. 2D echocardiogram long-axis section showing interventricular septal abscess.

\subsection{Case Report III}

It was about a 25-year-old patient, referred to the cardiology and internal medicine department of the University Hospital of Brazzaville for the treatment of infectious endocarditis, after probabilistic biantibiotics at a city clinic for two weeks.

Symptoms began three weeks before her admission with the progressive onset of exertional dyspnea classified as stage II by the NYHA, which became stage IV in a febrile context. It was associated with palpitations, chills, altered general condition and a dry cough.

On admission, the patient presented: polypnea ( $\mathrm{FR}=32 \mathrm{cycles} / \mathrm{min})$, oxygen saturation at $99 \%$ in ambient air, a weight of $52 \mathrm{~kg}$ (previous weight $60 \mathrm{~kg}$, i.e. a loss of $8 \mathrm{~kg}$ ), a height of $1.70 \mathrm{~cm}$. The temperature was $38.6^{\circ} \mathrm{C}$ and the $\mathrm{BP} 120 / 70$ $\mathrm{mmHg}$.

The remainder of the examination noted: a normal chest configuration, well-perceived and regular heart sounds, tachycardia at 105 beats/min, and proto-diastolic galloping noise. Note the absence of pericardial friction and splenomegaly.

- The chest X-ray (Figure 11) showed significant cardiomegaly, a cardio-thoracic ratio $(\mathrm{RCT}=66 \%)$, and venous redistribution towards the peaks. Free diaphragmatic and cardio-phrenic costo sac culverts.

The EKG showed sinus tachycardia at 100 beats per minute.

The 2D trans-thoracic cardiac ultrasound (Figure 11) coupled with Doppler revealed a moderately dilated left ventricle (ejection fraction: 51\%). The other aspects noted were: a heterogeneous intramural mass at the junction of the posterior wall of the left ventricle and the left atrium measuring $51 \mathrm{~mm}$ in diameter, two abscesses of the interventricular septum measuring $12 \mathrm{~mm}$ in diameter. The 


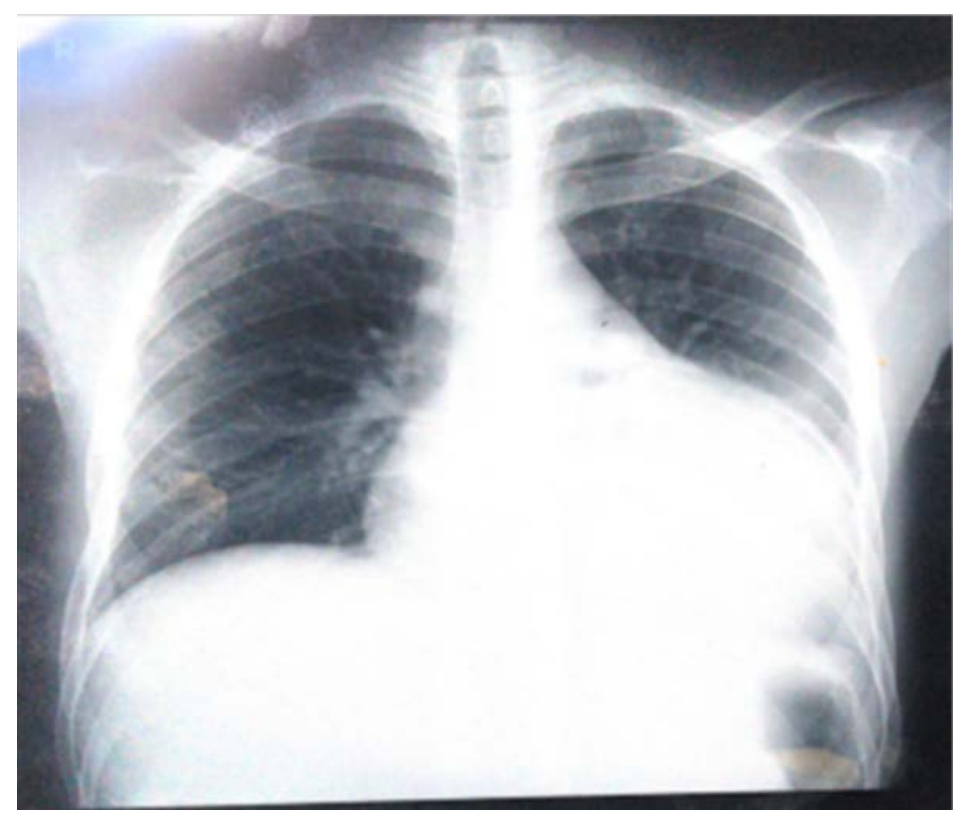

Figure 11. Frontal chest x-ray. Cardiomegaly, hilar stasis.

mitral profile was restrictive, and PAP was normal.

- Laboratory examinations made it possible to note: two negative blood cultures, negative retroviral (HIV) serology, CRP at $105 \mathrm{mg} / \mathrm{l}$; a VS at $60 \mathrm{~mm}$. Leukocytes were 12,800 cells $/ \mathrm{mm}^{3}$, hemoglobin $12.1 \mathrm{~g} / \mathrm{dl}$, platelets $202,000 / \mathrm{mm}^{3}$, and fasting blood sugar $0.71 \mathrm{~g} / \mathrm{l}$. The serum creatinine was $11 \mathrm{mg} / \mathrm{l}$.

The intramural mass noted on cardiac ultrasound (Figure 12) was explored by a chest CT scan with and without injection was performed (Figure 13 and Figure 14).

The diagnosis of infectious aortic endocarditis involving a native valve complicated by septal abscess and heart failure was retained. An intramural mass of the left heart was associated.

The medical treatment included: a sodium-reduced diet, digoxin $0.25 \mathrm{mg} / \mathrm{day}$, captopril $25 \mathrm{mg} 1$ tablet $\times 2 /$ day, intravenous furosemide $20 \mathrm{mg} \times 2 /$ day.

The course was marked by persistent fever and regression of signs of heart failure.

Due to insufficient technical facilities, medical evacuation abroad was selected.

The length of hospitalization was 16 days in addition to the two weeks stay in a private clinic. At the two-year check-up, the patient's condition remains stable hemodynamically and rhythmically. Adherence to maintenance cardiological treatment is good.

\section{Discussion}

\subsection{Epidemiological, Clinical and Paraclinical Aspects}

\subsubsection{Epidemiological Aspects}

1) Age

From this work focusing on three observations, we find the notion according 


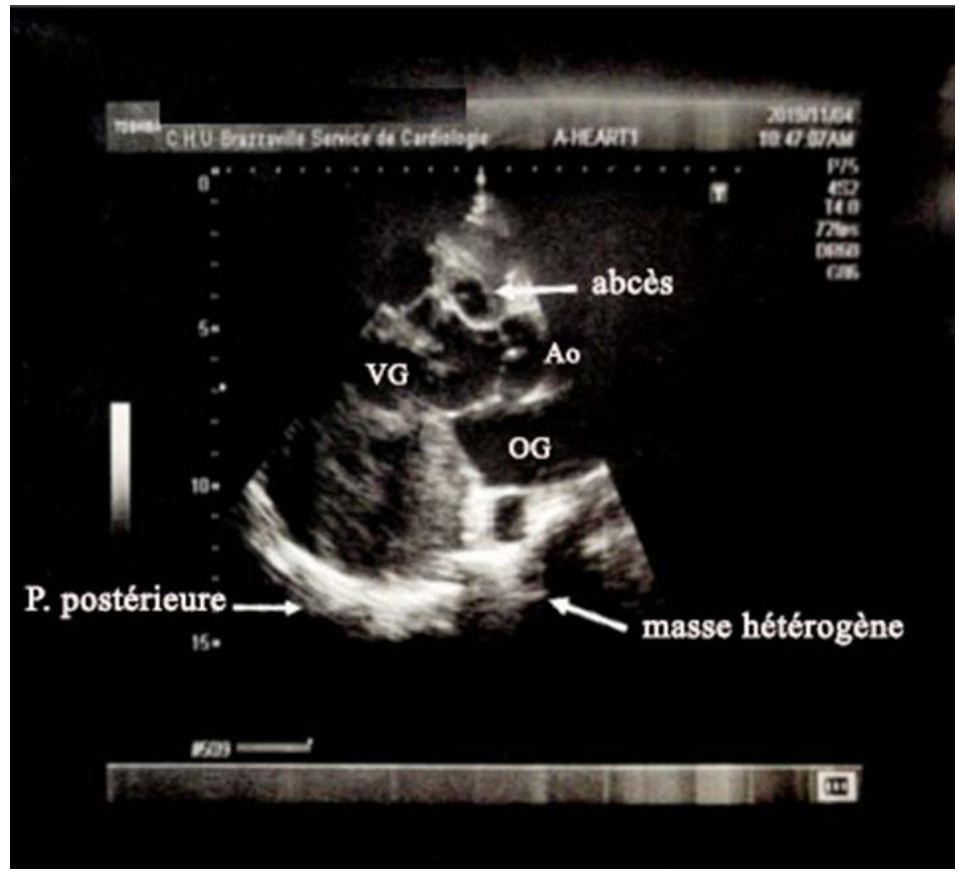

Figure 12. 2D ETT. Heterogeneous posterior wall mass, SIV abscess.

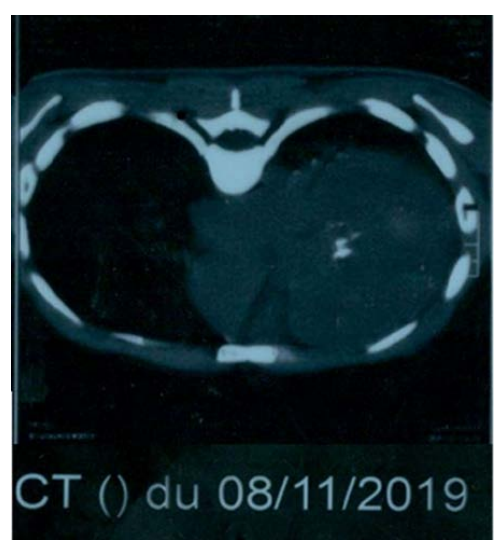

Figure 13. Chest CT scan without injection showing a cardiac mass with calcification.

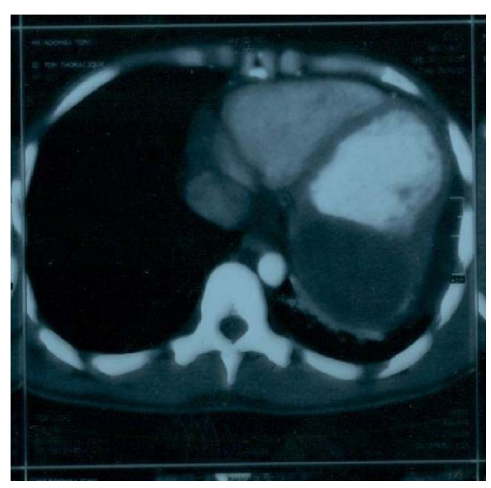

Figure 14. Chest CT scan with injection showing the 2 components of cardiac mass: liquid and solid. 
to which, IE preferentially affects young subjects in our context. In fact, the ages of our three patients were: 24,25 and 28 years old. In developed countries, the age of patients with IE is older. This is due to the greater frequency of degenerative valve disease and people with prosthetic heart valves [8] [9] [10] [11].

2) Gender

All of our patients were male. This may be explained by the small size of the sample due to the clinical form retained. The two previous Congolese series included more female subjects [8] [9].

3) Origin and socio-economic status of patients

All of our patients resided in Brazzaville. This observation could be explained by the places where patients are recruited (medical practices located in urban areas). We must add to this that the people of Brazzaville have easier access to the University Hospital of Brazzaville. This was the case for one of our patients who directly consulted the medical emergencies of the University Hospital of Brazzaville for a punch-down syncope.

One of our patients was a government employee; another unemployed graduate, and finally the last one, unemployed without any education.

\subsubsection{Clinical Aspects}

1) Functional signs

Dyspnea was the most frequently observed functional sign. Indeed, it was the reason for consultation for two of our three patients. Dyspnea is related to heart failure. The latter is the witness, in the subacute forms, of the late consultation period. Our patients consulted within an increasing timeframe of: three weeks (observation 3), four weeks (observation 1), five weeks (observation 2).

2) General signs

Among the general signs, fever was almost always present in most series, with a frequency of around $90 \%$ [12] [13]. It was observed in all our patients, between $38^{\circ} \mathrm{C}$ and $40^{\circ} \mathrm{C}$. The association with a deterioration in general condition is possible, as in all of our patients. Also, faced with a prolonged and unexplained fever in a patient with a heart murmur, the diagnosis of IE should be considered.

3) Cardiac signs

Pre-existing heart disease: in developing countries, rheumatic heart disease generally favors the occurrence of IE [8] [12] [14] [15]. In all of our cases, IE occurred on a native valve. IE involved the aortic valve in all cases, both the mitral and aortic valve in a single case. Our short series did not include tricuspid involvement, mainly involving clandestine abortions as previously highlighted in Brazzaville [8]. In the West and across the Atlantic, tricuspid AE is mainly observed in drug addicts and HIV-positive subjects [16]. Our three patients had negative HIV serology.

The existence of a congenital heart disease is also a risk factor for the occurrence of an IE [12] [16].

Prosthetic heart valves (PHV) are an undeniable point of call for IE. They are one of the causes of the increased frequency of the disease in developed coun- 
tries. Bouramoue et al.'s series of 39 IE cases included four patients with PHV [8].

4) Extra cardiac signs

Extracardiac signs are rarely reported in the different series [17] [18]. Splenomegaly is rarely found. Only one of our patients had presented with splenomegaly.

5) The entrance gate to the IS

There are several ways in which the germ is introduced into the body. The gateway is generally found in more than half of the cases and is predominantly oral. This was the case in only one of our patients who presented with several decayed teeth. This required stomatological management of the lesions observed [19] [20] [21] [22].

6) Type of infectious endocarditis

The IE was subacute in all of our cases, witnessing the prolonged fever consistently reported. However, for the case with syncopal AVB, an acute form can be discussed, due to the absence of dilation of the heart chambers. We thus affirm, after several authors, the predominance of subacute IE. It is worth highlighting the increase in acute variety in developed countries. One of the explanations is the appearance of new entry points (drug addiction ...) and the virulence of the germ, in particular Staphylococcus aureus [8] [9] [23] [24].

\subsection{Paraclinical Aspects}

\subsubsection{Blood Cultures}

In the literature, positive blood cultures are found in $80 \%$ to $90 \%$, negative blood cultures are relatively rare and represent $5 \%$ to $10 \%$. The most frequent germs are staphylococci and streptococci with no significant difference between the groups [25] [26] [27] [28]. On the other hand, in our work, the two blood cultures carried out in each case came back negative. This did not allow any germ to be isolated. These bacteriological results, which do not contribute to the diagnosis in our work, can be explained by the reduced number of blood cultures carried out due to the modest social condition of our patients. It should be noted that self-medication, common in our context (a case in our work), does not promote healing from IE.

\subsubsection{Ultrasound Aspects}

Cardiac ultrasound is an important part of the diagnosis of IE. However, transesophageal ultrasound has been shown to be superior to TTE in IE. It makes it possible to specify the diagnosis with a sensitivity of $90 \%$ and a specificity of more than $95 \%$. Ultrasound expression of the lesions is multiple. Endocardial lesions tend to spread much more, when they sit at the level of the aortic orifice. Peri-annular abscesses can be complicated by fistulizations, punctures and conductive disorders. Our study confirms these notions. In fact, our patients presented peri-annular and fusing septal abscesses, responsible for conductive disorders by damage to the bundle of His. The severe lesions are explained by the 
delay in diagnosis, following late consultations and blind antibiotic therapy.

\subsection{Complications}

The other lesions observed were: HF and abscesses.

- It is accepted that heart failure is the main complication of infectious endocarditis occurring on a native valve, especially the aortic valve, because the course is more prolonged in these endocarditis [12] [15]. Two of our patients had presented with HF.

TTE visualized: SIV abscesses (consistently); an annular abscess (in one case). In any case, no valve vegetation was visualized. ETO would have been of great help. In mitro-aortic insufficiency, a cardiac tumor of the posterior wall of the heart was associated. She was atrial and ventricular, heterogeneous on TTE, and exhibiting both a liquid and a solid component on the chest CT scan with injection.

- Two cases of atrioventricular conduction disorder were observed. In the literature [29], atrioventricular blocks secondary to septal abscesses generally complicate infectious endocarditis in $2 \%$ to $4 \%$ of cases. Other authors like Meine et al., [30] have noted higher rates: $26 \%$ of conduction abnormalities. These were BAV III, BAV II and BAV I, in a series of 137 cases of infectious endocarditis. Out of 15 cases of abscessed infectious endocarditis, eight cases of AVB were noted in a recent series [31]. High rates of conduction disturbance have also been reported by Choussat et al. [32]. From 233 cardiac abscesses, 20 cases of high degree AVB (II or III) only on aortic abscess were observed. Conduction abnormalities appear to be much more frequent and severe in abscessed endocarditis, especially in the presence of peri-aortic and septal abscesses. These irritate or compress the atrioventricular conduction pathways.

On the other hand, this finding is not always so clear, Danchin et al. [33] compared the evolutionary profile of 122 cases of infectious endocarditis with and without abscess of the aortic annulus and did not note any difference in the occurrence of atrioventricular conductive disorders.

\subsection{Therapeutic and Evolutionary Aspects}

The therapeutic approach for infectious endocarditis is multidisciplinary involving, among others, the cardiologist, the microbiologist, the infectious disease specialist and the surgeon. In our study, medical treatment reduced the signs of HF without, however, solving the problem of the infectious focus which required urgent surgery. However, the infectious syndrome was persistent. In view of this, surgery would have made it possible to put an end to the infectious process by flattening the abscesses, to restore the integrity of the atrioventricular conduction by the pause of a pacemaker and to set up an aortic valve replacement by an aortic valve. mechanical or biological prosthesis. Only one patient was operated. This therapeutic approach is described in the literature and it alone allows defin- 
itive cure of IE [29] [34] [35].

\section{Conclusion}

Infectious endocarditis is a universal, rare, but serious disease. DUKE's criteria integrating echocardiographic aspects allow its diagnosis. In our experience, infectious endocarditis occurs on a native valve, complications (abscesses whether or not associated with heart failure) reach the working population. It should be noted the greater difficulty of performing blood cultures according to standards, the diagnostic value of transesophageal ultrasound (not available), and the need for medical evacuation for surgical management. It is necessary to improve the technical platform.

\section{Conflicts of Interest}

The authors declare no conflict of interest.

\section{References}

[1] Hoen, B., Alla, F., Selton-Suty, C., Béguinot, I., Bouvet, A., Briançon, S., et al. (2002) Changing Profile of Infective Endocarditis: Results of a 1 Year Survey in France. $J A M A, 288,75-81$. https://doi.org/10.1001/jama.288.1.75

[2] Habib, G., Lancellotti, P., Antunes, M.J., Bongiorni, M.G., Casalta, J.P., et al. (2015) ESC Guidelines for the Management of Infective Endocarditis: The Task Force for the Management of Infective Endocarditis of the European Society of Cardiology (ESC). Endorsed by: European Association for Cardio-Thoracic Surgery (EACTS), the European Association of Nuclear Medicine (EANM). European Heart Journal, 36, 3075-3128.

[3] Nissen, H., Nielsen, P.F., Frederiksen, M., Helleberg, C. and Nielsen, J.S. (1992) Native Valve Infective Endocarditis in the General Population: A 10 Year Survey of the Clinical Picture during the 1980s. European Heart Journal, 12, 872-877.

https://doi.org/10.1093/oxfordjournals.eurheartj.a060285

[4] Issa, N., Dijos, M., Greib, C., Wirth, G., Peuchant, O., et al. (2016) Impact of an Endocarditis Team in the Management of 357 Infective Endocarditis. Open Forum Infectious Diseases, 3, 1122. https://doi.org/10.1093/ofid/ofw172.825

[5] Baddour, L.M., Wilson, W.R., Bayer, A.S., Fowler, V.G., Tleyjeh, I.M., et al. (2015) Infective Endocarditis in Adults: Diagnosis, Antimicrobial Therapy, and Management of Complications: A Scientific Statement for Healthcare Professionals from the American Heart Association. Circulation, 132, 1435-1486.

[6] Delahaye, J.P., Loire, R., Delahaye, F., Vandenesch, F. and Hoen, B. (2000) Endocardite Infectieuse. In: EMC Cardiologie, Elsevier SAS, Paris, 11-013-B-10, 25 p.

[7] Hoen, B. and Duval, X. (2013) Infective Endocarditis. The New England Journal of Medicine, 369, 784-785. https://doi.org/10.1056/NEJMc1307282

[8] Bouramoue, et al. (1992) Endocardite Infectieuse: Expérience d'un service Brazzavillois: A propos de 47 cas. Cardiologie Tropicale, 18, 134.

[9] Ikama, M.S., Nkalla-Lambi, M., Kimbally-Kaky, G., Loumouamou, M.L. and Nkoua, J.L. (2013) Profil de l'endocarditeinfectieuse au CHU de Brazzaville. Médecine et Santé Tropicales, 23, 89-92. https://doi.org/10.1684/mst.2013.0151

[10] Papakonstantinou, P.E., Samonis, G. andrianaki, A.M., Christofaki, M., Dimopou- 
lou, D., Papadakis, J., et al. (2018) Epidemiology, Microbiological and Clinical Features, Treatment, and Outcomes of Infective Endocarditis in Crete, Greece. Infection \& Chemotherapy, 50, 21-28. https://doi.org/10.3947/ic.2018.50.1.21

[11] Tribak, M., Konaté, M., Elhassani, A., Mahfoudi, L., Jaabari, I., Elkenassi, F., et al. (2016) Endocardite Infectieuse Aortique: Intérêt de la chirurgie. À propos de 48 cas. Annales de Cardiologie et d'Angéiologie, 65, 15-20.

https://doi.org/10.1016/j.ancard.2015.02.003

[12] Tornos, P., Lung, B., Permanyer-Miralda, G., et al. (2005) Infective Endocarditis in Europe: Lessons from the Euro Heart Survey. Heart, 91, 571-575. https://doi.org/10.1136/hrt.2003.032128

[13] Van den Brink, F., Hasenaar, J., Winia, V., Klomp, M., Van Vlies, B., Nicastia, D., et al. (2016) Prognostic Factors in Infective Endocarditis in General Hospitals in the Netherlands. Netherlands Heart Journal, 24, 717-721. https://doi.org/10.1007/s12471-016-0846-2

[14] Brandenburg, R.O., Guiliani, E.R., Wilson, W.R. and Geraci, J.E. (1983) Infective Endocarditis. A 25 Year Overview of Diagnosis and Therapy. American Journal of Cardiology, 1, 280-291. https://doi.org/10.1016/S0735-1097(83)80029-1

[15] Federspiel, C. (2012) Caractéristiques et impact thérapeutique et pronostique des complications neurologiques de l'endocardite infectieuse. Thèse de Doctoratd, Université, Sciences du vivant, Médecinehumaine et pathologie, Université de Lorraine Faculté de Médecine de Nancy, Nancy.

[16] Ohshima, H., Itaoka, Y., Ohno, M., Hara, K., Kashida, M., Kuwako, K. and Yamagushi, T. (1990) A Case of Right Sided Infective Endocarditis in a Drug Addict. Kokyu to Junkan, 38, 277-281.

[17] Spelman, D. and Sexton, D.J. (2020) Complications and Outcome of Infective Endocarditis. Up to Date (Updated May). https://www.uptodate.com

[18] Bonneau, E. and Jourde, M. (2003) Foyers infectieux d'origine bucco-dentaire. Commission de prévention et santépublique. Bull. Acad. Natle. Chir. Dent. n, 46.

[19] Roche, Y. (2002) Gestes et situations àrisque d'endocardite infectieuse d'origine bucco-dentaire. Medecine et maladies infectieuses, 32, 628-634. https://doi.org/10.1016/S0399-077X(02)00427-4

[20] Chirillo, F., Scotton, P., Rocco, F., Rigoli, R., Borsatto, F., Pedrocco, A., et al. (2013) Impact of a Multidisciplinary Management Strategy on the Outcome of Patients with Native Valve Infective Endocarditis. American Journal of Cardiology, 112, 1171-1176. https://doi.org/10.1016/j.amjcard.2013.05.060

[21] Foisel, C. (2009) Endocardite Infectieuse du sujet toxicomane. Thèse de Doctorat d'Université, Sciences du vivant, Médecine humaine et pathologie, Université Henri Poincaré, Nancy 1, Faculté de Médecine de Nancy, Nancy.

[22] Li, J.S., Sexton, D.J., Mick, N., Nettles, R., Fowler, V.G., Ryan, T., et al. (2000) Proposed Modifications to the Duke Criteria for the Diagnosis of Infective Endocarditis. Clinical Infectious Diseases, 30, 633-638. https://doi.org/10.1086/313753

[23] Hill, E.E., Herijgers, P., Claus, P., Vanderschueren, S., Herregods, M.C. and Peetermans, W.E. (2007) Infective Endocarditis: Changing Epidemiology and Predictors of 6-Month Mortality: A Prospective Cohort Study. European Heart Journal, 28, 196-203. https://doi.org/10.1093/eurheartj/ehl427

[24] Delahaye, J.P. (2006) Endocardites infectieuses. Traité de médecine, troisième édition. Paris: Flammarion Médecine-Sciences, 1578-1585.

[25] Habib, G., Hoen, B., Tornos, P., et al. (2009) Guidelines on the Prevention, Diagno- 
sis, and Treatment of Infective Endocarditis (New Version 2009). The Task Force on the Prevention, Diagnosis, and Treatment of Infective Endocarditis of the European Society of Cardiology (ESC). European Heart Journal, 30, 2369-2413.

[26] Tissot-Dupont, H., Casalta, J.P., Gouriet, F., Hubert, S., Salaun, E., Habib, G., et al. (2017) International Experts' Practice in the Antibiotic Therapy of Infective Endocarditis Is Not Following the Guidelines. Clinical Microbiology and Infection, 23, 736-739.

[27] Tornos, P., Iung, B., Permanyer-Miralda, G., Baron, G., Delahaye, F., Gohlke-Bärwolf, C., et al. (2005) Infective Endocarditis in Europe: Lessons from the Euro Heart Survey. Heart, 91, 571-575. https://doi.org/10.1136/hrt.2003.032128

[28] Chu, V.H., Park, L.P., Athan, E., Delahaye, F., Freiberger, T., Lamas, C., et al. (2015) Association between Surgical Indications, Operative Risk, and Clinical Outcome in Infective Endocarditis: A Prospective Study from the International Collaboration on Endocarditis. Circulation, 131, 131-140. https://doi.org/10.1161/CIRCULATIONAHA.114.012461

[29] Berlin, J.A., Abrutyn, E., Strom, B.L., Kinman, J.L., Levison, M.E., Karzeniowski, O.M., et al. (1995) Incidence of Infective Endocarditis in the Delaware Valley, 1988-1990. The American Journal of Cardiology, 76, 933-936. https://doi.org/10.1016/S0002-9149(99)80264-1

[30] Groupe d'enquête de l'Association pour l'étude et la prévention de l'endocardite infectieuse (AEPEI) (2003) Modifications du profil de l'endo-cardite infectieuse en France. Résultats d'une enquête épidémiologique conduite sur un an. Archives des Maladies du Coeur et des Vaisseaux, 96, 111-120.

[31] Rosamel, P., Cervantes, M., Tristan, A., et al. (2005) Active Infectious Endocarditis: Postoperative Outcome. JCTVA, 19, 435-439.

https://doi.org/10.1053/j.jvca.2005.05.002

[32] Choussat, R., Thomas, D., Isnard, R., Michel, P.C., Lung, B., Mathieu, M., et al. (1999) Perivalvular Abscesses Associated with Endocarditis. Clinical Features and Prognostic Factors of Overall Survival in a Série of 233 Cases. European Heart Journal, 20, 232-241. https://doi.org/10.1053/euhj.1998.1240

[33] Danchin, N., Retourmay, G., Stchepinski, O., SeltonSuty, C., Voiriot, P., Contot, P., et al. (1999) Comparison of Long-Term Outcomes in Patients with or without Aortic Ring Abscess Treated Surgically for Aortic Valve Infective Endocarditis. Heart, 81, 177-181. https://doi.org/10.1136/hrt.81.2.177

[34] Loobuyck, V. (2016) Endocardite Aortique Aigue de l'adultejeune: Résultats chirurgicaux à long terme (intervention de Ross, bioprothèses, prothèses mécaniques) Thèse de Doctorat d'Université, Sciences du vivant, Médecine Humaine et pathologie, Université du Droit et de la Santé Faculté de Médecine Henri Warembourg, Lille.

[35] Van der meer, J.T., Van wijk, W., Thompson, J., Vandenbroucke, J.P., Valkenburg, H.A. and Michel, M.F. (1992) Efficacy of Antibiotic Prophylaxis for Prevention of Native-Valve Endocarditis. The Lancet, 339, 135-139. https://doi.org/10.1016/0140-6736(92)90207-I 